\title{
Experimental study of influence of inlet geometry on thermal stratification in thermal energy storage during charging process
}

\author{
Petr Švarc ${ }^{1, \text { a }}$, Jan Seidl ${ }^{1}$ and Václav Dvoř́ák ${ }^{1}$ \\ ${ }^{1}$ Technical University of Liberec, Department of Power Engineering Equipment, 46117 Liberec, Czech Republic
}

\begin{abstract}
Various analyses of charging processes of real single-medium thermal energy storage were applied in this work. Two different inlet geometries of direct intakes into thermal energy storage were investigated for the process of charging in Richardson numbers 0.4 and 15 . Temperature distributions for both cases are shown and compared in selected time steps. Several simple methods for assessment of an ability to maintain and support thermal stratification during charging processes were compared with exergy analysis.
\end{abstract}

\section{Introduction}

Thermal stratification in water-thermal energy storages can improve quality of obtained thermal energy, especially in the case of low temperature heating systems. Many authors have analysed thermal stratification in hot and cold water tanks of many different designs and many different analyses have been applied for assessments of storing, charging and discharging processes. The result is that the ability to support the thermal stratification inside the storage can be influenced by many factors and therefore it is desirable to have an indicator of its performance.

Thermal storages are usually equipped with some inbuilds to support stratification during charging, storing and discharging processes or just with a simple intake through the storage wall. The simplest variations are commonly used for their applicability and in this work the simple side inlet into the experimental thermal energy storage was investigated and compared with the geometry of the charging inlet which, in principle, does not support thermal stratification.

\section{Assessment of stratification}

Several ways for assessment of the thermal stratification or a determination of the stratification efficiency in an operation cycle have been given by authors e.g. $[1,2,3]$. Three approaches are commonly used for their simple applicability for field measured data and were chosen for evaluation: thermocline thickness, equivalent lost tank height [4] and MIX number [5]. For the thermal performance evaluation, the exergy analyses [6] were chosen as another method for assessment.

The most commonly used measure of thermal performance is the thermocline thickness. It defines a portion of the tank height that contains mixed region. Although it does not describe performance, it is often used from the reason that is easily understood. The definition can be state in terms of a dimensionless temperature $\Theta$

$$
\Theta=\frac{T(y, t)-T_{\min }}{T_{\max }-T_{\min }},
$$

where $T_{\min }(\mathrm{K})$ is the minimum temperature inside water storage tank, $T_{\max }(\mathrm{K})$ is the maximum temperature in the storage which is corresponding the inlet temperature. $T(y, t)(\mathrm{K})$ represents measured temperature of every level $y(\mathrm{~m})$ in the storage in time. In the next step, it is only selected a limitation of each end on the temperature profile, often $10 \%$ or $15 \%$. The thermocline thickness is thus the distance between the points on the temperature profile. The limitation of $10 \%$ was selected in this study.

The equivalent lost tank height $(E L H)$ is a generalized expression for lost due to the mixing and conduction during the charging and discharging process. For charging process, it is defined by a spatial integral from the point where temperature is equal to the temperature of incoming fluid to the point on the thermocline where the temperature has the limiting value. The definition of the limiting value is various, but for simplicity a fixed value of $\Theta=0.5$ is used as a centre of the thermocline.

The lost capacity for a charge cycle is calculated by integrating the area enclosed by the temperature profile and the average inlet temperature in every time. For discrete volume elements of height $\Delta y$, the integral is approximated as a summation

$$
C_{\text {lost }}(t)=\sum \rho A c_{p}\left(T_{\max }-T(y, t)\right) \Delta y,
$$

\footnotetext{
a petr.svarc@tul.cz
} 
where $\rho\left(\mathrm{kg} \cdot \mathrm{m}^{-3}\right)$ is referent density of water, $A\left(\mathrm{~m}^{2}\right)$ is the cross section area of the storage, $c_{p}\left(\mathrm{~J} \cdot \mathrm{kg}^{-1} \cdot \mathrm{K}^{-1}\right)$ is the specific heat.

The equivalent lost tank height $(E L H)$ defined by authors in work [4] is divided by theoretical ideal capacity with unit depth of water in the same tank plan area. Therefore $E L H$ has units of length.

$$
E L H=\frac{C_{\text {lost }}(t)}{\rho A c_{p}\left(T_{\max }-T_{\min }\right) \cdot \sum \Delta y} .
$$

The MIX number is also dimensionless value defined by authors in work [5] and widely used for simple using and easy understanding. The MIX number is based on the so called momentum of energy and it expresses the degree of mixing that occurs during a charging or a discharging process. The momentum of energy in the different horizontal layers along the tank height is acquired as the energy of every layer weighted by layers height. The MIX number is the difference of the momentum of energy between a perfectly stratified storage $\left(M_{e n, \text { strat }}\right)$ and the experimental storage $\left(M_{e n, \text { exp }}\right)$ divided by the difference of the momentum of energy between a perfectly stratified storage and fully mixed storage $\left(M_{e n, m i x}\right)$

$$
M I X=\frac{M_{e n, \text { strat }}-M_{e n, \exp }}{M_{e n, \text { strat }}-M_{e n, m i x}} .
$$

The MIX number varies from zero for perfectly stratified tank to one for completely mixed volume. As a stratification index the value $1-M I X$ is commonly used.

The exergy assessment is a concept based on both the first and the second laws of thermodynamics. Exergy is able to determinate the loss of incoming energy to the reference system Exergy loss, or loss of work potential, is associated irreversible process therefore exergy analysis enables the exploration of thermodynamic losses. The net incoming exergy $\dot{E}_{n e t}(t)\left(\mathrm{J} \cdot \mathrm{s}^{-1}\right)$ into the storage in every time of process could be expressed as

$$
\begin{gathered}
\dot{E}_{\text {net }}(t)=\dot{E}_{\text {in }}(t)-\dot{E}_{\text {out }}(t), \\
\dot{E}_{\text {net }}(t)=\dot{m} c_{p} T_{\min }\left(\frac{T_{\max }-T_{\text {out }}(t)}{T_{\min }}-\ln \left(\frac{T_{\max }}{T_{\text {out }}(t)}\right)\right),
\end{gathered}
$$

where $\dot{m}\left(\mathrm{~kg} \cdot \mathrm{s}^{-1}\right)$ is mass flow rate of incoming water, $T_{\text {out }}(t)(\mathrm{K})$ is temperature of outflow water in time, $\dot{E}_{\text {in }}(t)\left(\mathrm{J} \cdot \mathrm{s}^{-1}\right)$ and $\dot{E}_{\text {out }}(t)\left(\mathrm{J} \cdot \mathrm{s}^{-1}\right)$ is the inflowing and outflowing exergy in the storage. For the exergy stored in the tank $E_{\text {stored }}(t)(\mathrm{J})$ in any time could be written

$$
E_{\text {stored }}(t)=\frac{m c_{p} T_{\min }}{H} \sum \Delta y \cdot\left(\frac{T(y, t)}{T_{\text {out }}(t)}-1-\ln \left(\frac{T(y, t)}{T_{\text {out }}(t)}\right)\right)
$$

where $m(\mathrm{~kg})$ is the weight of the water inside the tank, $H(\mathrm{~m})$ is active height of the tank. The second law efficiency of the charging process could be defined as

$$
\eta_{I I}(t)=\frac{E_{\text {stored }}(t)}{\sum \dot{E}_{n e t}(t) \cdot \Delta t},
$$

where $\Delta t(\mathrm{~s})$ is time of charging.

\section{Experiments}

Figure 1 shows arrangement of the experimental devices. It consists of a thermal energy storage of total volume $0.903\left(\mathrm{~m}^{3}\right)$, the hot water supply system and the system for acquisition of the temperature and flow data. The hot water supply system provided constant inlet temperature of charging water. The mass flow rate was monitored by a flow meter with accuracy $\pm 1 \%$. All used thermocouples were calibrated for accuracy $\pm 0.1^{\circ} \mathrm{C}$. The position of the thermocouples inside the water tank was set into three vertical lines with 19 thermocouples in every line and with the same distance.

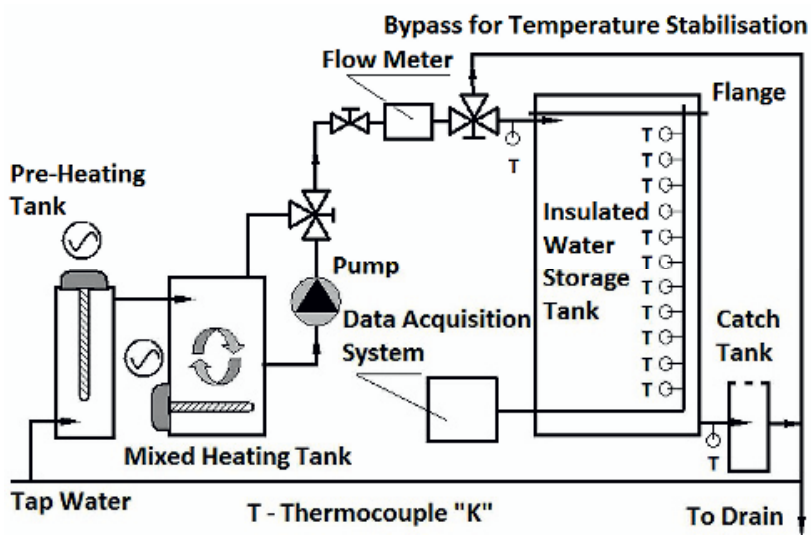

Figure 1. Schematic draw of the experimental arrangement for charging with the side and downward inlets.

Removable upper part of the tank allows installing various builds inside the storage. The cover and the body of the tank are connected by a flange. The charging inlets were in upper part of the storage in both investigated cases. The side inlet is commonly used and therefor was chosen for the investigation. A downward axial inlet was chosen as the worst case of charging system with the worst maintain and evolution of the thermal stratification inside the water tank. Both cases are shown in figure 2.

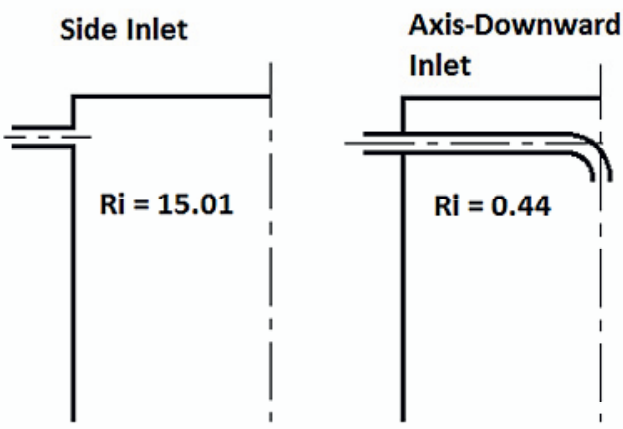

Figure 2. Inlets in both investigated cases. Left - the side inlet of the charging water, right side - the downwards direct axis inlet. 
Charging mass flow rate in both cases was set to $400\left(\mathrm{~kg} \cdot \mathrm{h}^{-1}\right)$ with charging temperature incoming fluid approximately $45^{\circ} \mathrm{C}$. Initial temperature of the water inside tank was approximately $15.5^{\circ} \mathrm{C}$ for the side inlet and for the downward inlet.

\section{Results and discussion}

The charging time was defined as a dimensionless value using mass flow rate and time step divided by whole weight of the storage content. Dimensionless time could be simply expressed as

$$
t^{*}=\frac{\dot{m} \Delta t}{m}
$$

where $\Delta t(\mathrm{~s})$ is again time of the charging process. For further use and simple comparison of the results dimensionless height of the tank was defined as a ratio of vertical length and active height of the tank

$$
y^{*}=\frac{y}{H} \text {. }
$$

The effect of inlet geometry on stratification in thermal energy storages was reported in earlier studies, e.g. in [7]. For easier assessment of both inlets the Richardson number was calculated as

$$
R i=\frac{\Delta \rho g H}{\rho_{m} w_{i n}^{2}},
$$

where $\Delta \rho\left(\mathrm{kg} \cdot \mathrm{m}^{-3}\right)$ is density difference of water in initial and inlet conditions, $\rho_{m}\left(\mathrm{~kg} \cdot \mathrm{m}^{-3}\right)$ is the mean density of water inside the storage, $g\left(\mathrm{~m} \cdot \mathrm{s}^{-2}\right)$ is the acceleration of gravity and $w^{2}$ in $\left(\mathrm{m} \cdot \mathrm{s}^{-1}\right)$ is the velocity of incoming fluid. The Richardson number during charging process was approximately in range of 15 for side inlet and of 0.4 for downward inlet. Although the value of Richardson number for downward inlet is under unity, it is still higher than the critical value of $R i=0.24$ below which the stratification does not occur [8].

The temperature profiles of the side inlet and downward inlet are shown in figures 3 and 4 in the dimensionless time from 0.25 to 1 and dimensionless height $y^{*}$.

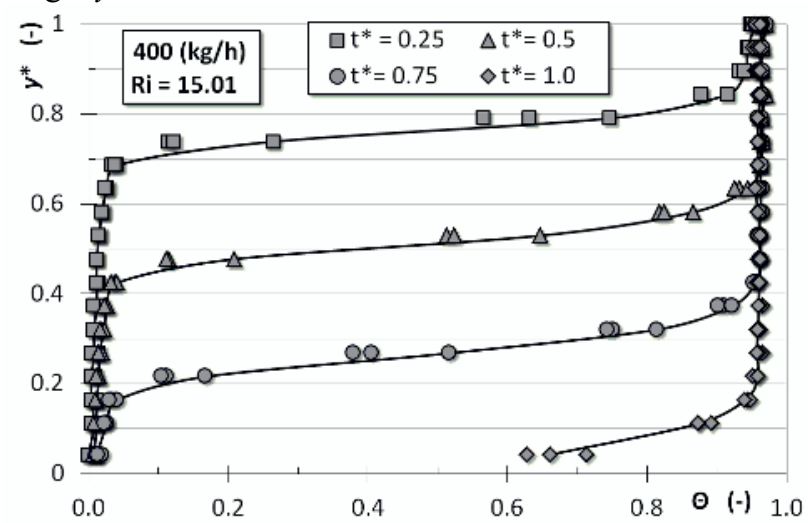

Figure 3. Temperature profiles during charging process with side inlet.
The influence of the geometry of both inlets is well seen in both figures 3 and 4 . The temperature of upper layers in the case of side inlet, see figure 3 , is progressively approaching the inlet temperature. The temperature distribution during whole process seems to have a piston flow along the vertical length of the storage. For the processing of both cases the maximum temperature was evaluated as a maximal value occurs during whole charging cycle. This brings the distance of the temperature inside the storage and unity of the dimensionless temperature $\Theta$.

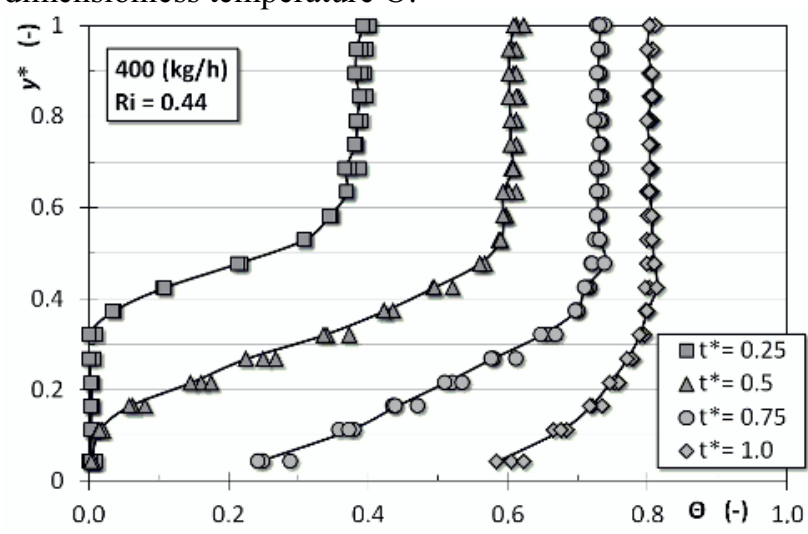

Figure 4. Temperature profiles during charging process with downward inlet.

In the case of downward inlet, see figure 4, the mixing of greater volume occurs and the temperature field is affected more in the depth of the storage. This leads to lower temperature of upper layers and more noticeable distance between temperatures of the upper layers and the inlet in all reference dimensionless time steps. In both cases, the outlet temperature in dimensionless time close to unity is different from initial temperature of storage and it is caused by the mixing of the incoming fluid and the fluid inside the storage with lower temperature. This brings losses in the form of outflowing energy. Of course, these losses occur earlier when the mixing inside the storage influences greater volume and therefore the thermocline thickness is greater. This fact can be seen in figure 5 , where the time development of the thermocline thickness with limitations $10 \%$ based on the dimensionless temperature is shown.

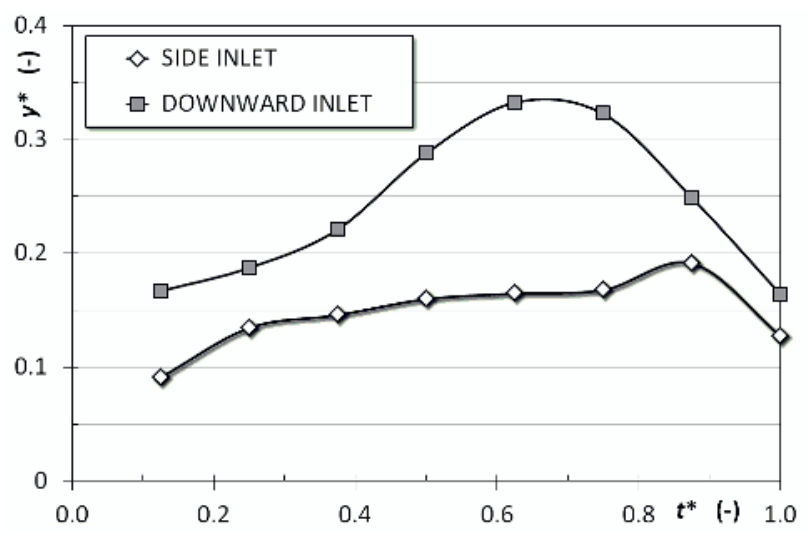

Figure 5. Development of thermocline thickness in dimensionless time based on the dimensionless temperature and limitation $10 \%$ in charging process for side and downward inlets. 
The thermocline thickness is involved by the mixing as mentioned above. It increases during the process in both cases, but more significantly for the downward inlet due to the mixing of bigger volume. The thermocline thickness decreased in both cases when the outflowing temperature became higher than the initial temperature in the storage. The decreasing for the downward inlet started before the dimensionless time reached the value of 0.75 but the decreasing of the thermocline thickness for the side inlet was apparent after 0.8. Although the differences between both reference cases are obvious and it is qualitatively evident, which inlet geometry is more favourable to maintain the thermal stratification within the storage during charging cycle, a quantitative view would be more appropriate.

The index 1 - MIX number is widely used for an assessment of thermal energy storages for its simplicity. The dimensionless time developments for both reference cases are shown in figure 6.

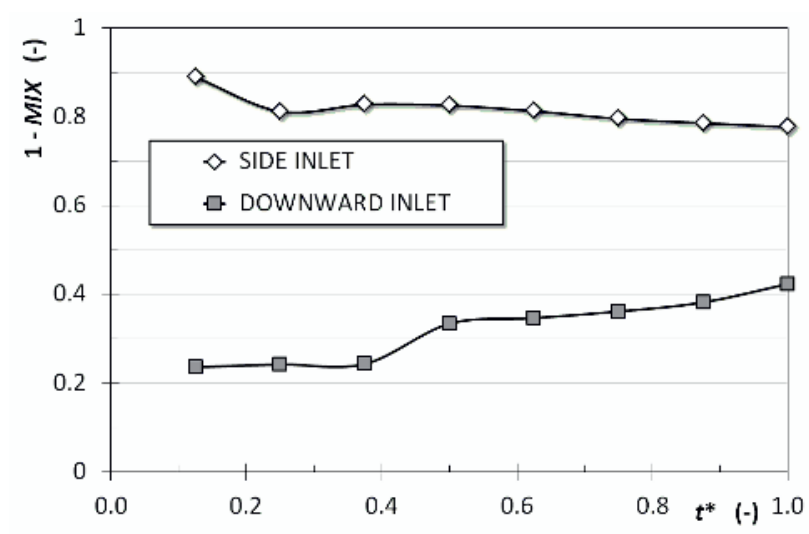

Figure 6. Efficiency of charging process of both reference cases based on the $M I X$ number.

The efficiency of the charging process of the side inlet appears to be constant or with a slowly declining trend. For the reference case with charging by downward inlet, the incoming fluid affects the temperature field more in depth of the storage and the temperature of the inner layers differ obviously from the inlet temperature. During the charging process the temperature of the surrounding near of the inlet slowly increases and the temperature difference between inlet and water inside of the storage is lower and thus the losses are lower. The momentum of energy of the experiment increases and $M I X$ number declines. The MIX number can be in conflict to the assumption of higher momentum of energy of the perfectly stratified content than the momentum of energy of the real storage especially during discharging cycles. Although, the $M I X$ number is suitable for charging, it is often used for discharging as well.

As was stated above, the $E L H$ is generalized expression for the lost capacity. To reach an indicator for easy comparison of various storage tanks, the lost capacity was related to the theoretical capacity per unit of depth of the storage with the same plan area. Thus the $E L H$ number has unity of length and expressed a layer of water that would have the same capacity loss as the given process. The equivalent lost height during charging process is shown in figure 7 . The $E L H$ of the downward inlet is noticeably higher than for the side inlet, where the $E L H$ is oscillated around the height of $0.1(\mathrm{~m})$. On the contrary the $E L H$ of the downward inlet slowly increases by the increasing the thermocline thickness as is shown in figure 5 till the instant when the temperature of the outflowing water is equal to the centre of the thermocline defined by $\Theta=0.5$. Thereafter the trend is declining.

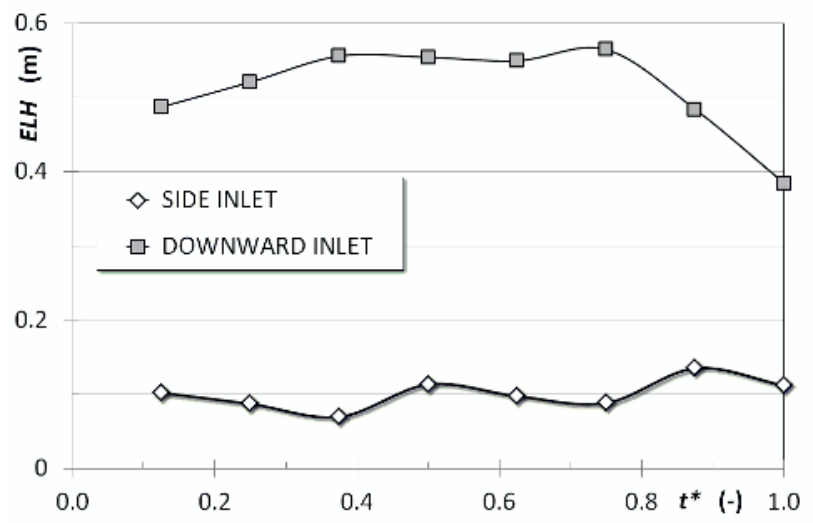

Figure 7. The equivalent lost height $E L H$ during charging process for side and downward inlet.

The efficiency based on the comparison of the stored exergy of the real process to the theoretical net exergy inflowing into the storage according the work [5] in both cases is shown in figure 8 . The efficiency of the side inlet is significantly higher than the efficiency of the downward inlet. This is in conformity with other results. The efficiency in both cases grows due to the decreasing the temperature difference between incoming fluid and the fluid in surrounding of the inlet. This yields to lower losses caused by mixing of the volumes with different temperature.

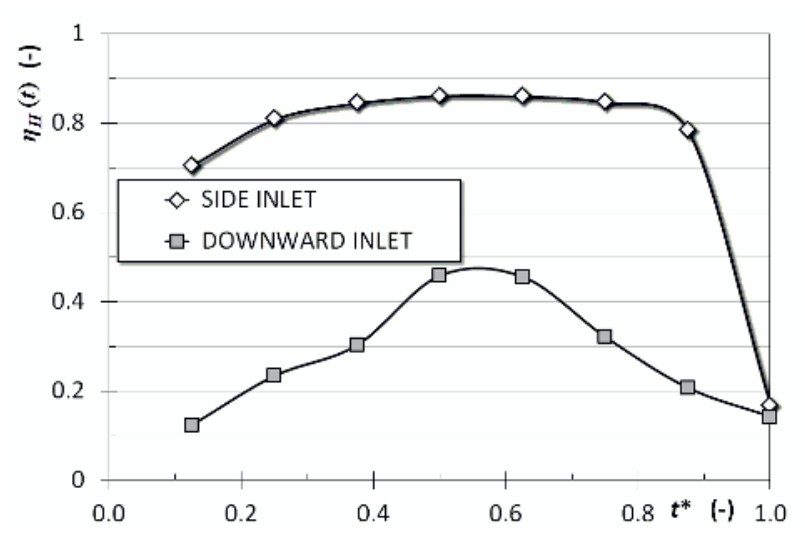

Figure 8. The efficiency development based on the exergy concept.

The efficiency drop during the charging cycle of both referent cases is caused by losses in the form of outflowing exergy. The outflow temperature is higher than the initial temperature and therefore the outflowing losses occur. It is well distinct that for downward inlet the losses in the form of outflowing exergy occur earlier and when it happens. This is in agreement with temperature distribution and the development of the thermocline thickness. Great drop of efficiency based on exergy concept is also in the charging process of the side inlet. Although it appears later the decrease is greater and the 
efficiency in the end of the process is lower than at the beginning. However the net incoming exergy is considered as an adiabatic process and for simplicity only outflowing losses are included to the charge cycle the real data for stored exergy can encompass losses to the ambient.

\section{CONCLUSION}

Two different inlets into the storage were investigated and results were compared by several commonly used methods. The side and the downward inlet were measured during charging process to acquire the temperature fields. Obtained data were compared with the help of the thermocline thickness, MIX number, equivalent lost height $(E L H)$ and efficiency based on the exergy concept. (1) The thermocline thickness and the equivalent lost height have declining progress after half of the charging cycle. When the temperature of the outflowing fluid was higher than was the initial temperature, the thermocline thickness declined which is shown in figure 3 for $t^{*}=1$ and in figure 4 for $t^{*}=0.75$ and 1. The equivalent lost height has similar declining progress. From definition of the limiting value of the lost capacity $\Theta=0.5$ follows that when the limiting value is equal to outflowing fluid temperature, the lost capacity starts to decrease. Although, the decrease of the thermocline thickness and ELH seem to be a positive effect, it is caused by losses in the form of outflowing energy. The $M I X$ number is affected as well when the momentum of the energy of the experiment decreases by outflowing energy. These examples show that it is appropriate to observe also the energy content of the storage. The efficiency based on the exergy concept can indicate the losses in the form of outflowing energy by the efficiency progress drop as is shown in figure 8 . When the outflowing exergy $\dot{E}_{\text {out }}(t)$ increases the net incoming exergy declines and similarly does the efficiency of the process.

\section{Acknowledgment}

This project was realized with financial support by the University Development Fund of the Czech Ministry of Education, Youth and Sports, grant no. 571/2013/G1 and project SGS 28000.

\section{References}

1. Y. H. Zurigat, A. J. Ghajar, Thermal Energy Storage - Systems and Applications, Eds. Dincer \& Rosen. Wiley, p. 264-270, (2002).

2. V. Panthalookaran, W. Heidemann, H. MüllerSteinhagen, Sol. Ener. 81, 1043-1054, (2007).

3. M. Y. Haller, C. A. Cruickshank, W. Streicher, S. J. Harrison, E. Andersen, S. Furbo, Sol. Ener. 83, p. 1847-1860, (2009).

4. A. Musser, W. P. Bahnfleth, ASHRAE Transact., 104, p. 366 - 376, (1998).
5. J. H. Davidson, D. A. Adams, J. A. Müller, ASME Jour. of Sol. Ener. Eng. 116, p. 94 - 99, (1994).

6. A. Bejan, G. Tsatsaronis, M. Moran, Thermal Design \& Optimization, (1996).

7. Y. H. Zurigat, A. J. Ghajar, P. M. Moretti, Appl. Ener. 30, p. 99-111, (1988).

8. B. J. Sliwinski, A. R. Mech T. S. Shih, Proceed. of the Sixth Int. Heat Trans. Conf. 4, p.149-154, (1978).

9. Y. H. Zurigat, K. J. Maloney A. J. Ghajar, Transac. of ASME, 204, p. 204-210, (1989).

10. A. Musser, W. P. Bahnfleth, HVAC\&R Research 7, p. 31-50, (2001).

11. J. Waluyo, M. A. A. Majid, Jour. of Appl. Sc. 11, p. 1642-1647, (2001). 